\title{
Barriers and facilitators to treatment among patients with newly diagnosed hypertension in Nepal
}

\author{
Sachita Shrestha, ${ }^{1,2}$ Archana Shrestha, ${ }^{3}$ Rajendra P Koju, ${ }^{1,4,5}$ James P LoGerfo, ${ }^{1,6}$ \\ Biraj Man Karmacharya, ${ }^{5,7}$ Nona Sotoodehnia, ${ }^{8}$ Annette L Fitzpatrick ${ }^{1,9,10}$
}

\begin{abstract}
${ }^{1}$ Department of Global Health, University of Washington, Seattle, Washington, USA ${ }^{2}$ Department of Health Outcomes and Biomedical Informatics, University of Florida, Gainesville, Florida, USA ${ }^{3}$ Department of Epidemiology, Harvard T H Chan School of Public Health, Boston, Massachusetts, USA ${ }^{4}$ Department of Cardiology, Dhulikhel Hospital-Kathmandu University Hospital, Dhulikhel, Nepal

${ }^{5}$ Department of Community Medicine, Kathmandu University School of Medical Sciences, Dhulikhel, Nepal

${ }^{6}$ Department of Medicine, University of Washington, Seattle, Washington, USA

${ }^{7}$ Department of Community Programs, Dhulikhel HospitalKathmandu University Hospital, Dhulikhel, Nepal

${ }^{8}$ Division of Cardiology, University of Washington, Seattle, Washington, USA ${ }^{9}$ Department of Epidemiology, University of Washington, Seattle, Washington, USA ${ }^{10}$ Department of Family Medicine, University of Washington, Seattle, Washington, USA
\end{abstract}

\section{Correspondence to}

Sachita Shrestha, Department of Health Outcomes and Biomedical Informatics, University of Florida,

Gainesville, Florida 32608, USA; sachizshrestha@gmail.com

Received 4 April 2018 Revised 22 July 2018 Accepted 30 July 2018

\section{Check for updates}

(C) Author(s) (or their employer(s)) 2018. No commercial re-use. See rights and permissions. Published by BMJ.

To cite: Shrestha $S$, Shrestha A, Koju RP, et al. Heart Asia

2018;10:e011047.

doi:10.1136/

heartasia-2018-011047
ABSTRACT

Objective Hypertension is a significant and rising burden in Nepal. The disease remains undetected and inadequately managed. However, no studies have been conducted to understand the inhibiting and facilitating factors to hypertension treatment among newly diagnosed cases. This qualitative study aimed to explore barriers and facilitators to treatment among patients with newly diagnosed hypertension aged $\geq 18$ years in Dhulikhel, Nepal.

Methods We conducted seven focus group discussions with 35 patients with newly diagnosed hypertension identified through community surveillance of the Dhulikhel Heart Study, an observational cohort of Dhulikhel Hospital, Kathmandu University. Audiotaped discussions were transcribed, inductively coded and analysed by the thematic framework method using Atlas. ti V.7.

Results Hypertension was viewed as a rising problem in the community. Participants had limited knowledge and many misbeliefs regarding hypertension and its treatment. The major barriers included absence of symptoms, reluctance to take medicine, low perceived seriousness of the disease, challenges in behaviour change (diet and exercise), lack of family support, and lack of communication and trust with the provider. The major reported facilitating factors were fear of consequences of the disease, and family support in controlling diet and adhering to treatment.

Conclusions A number of factors emerged as barriers and facilitators to hypertension treatment. This information can be useful in designing appropriate health interventions to improve hypertension management.

\section{INTRODUCTION}

Hypertension is the leading risk factor for cardiovascular disease (CVD) and mortality worldwide, and is responsible for $13 \%$ of the total deaths and $7 \%$ of the global burden of disease. ${ }^{12}$ One out of three adults is affected by hypertension in South-East Asian countries, including Nepal. ${ }^{3}$ Nepal is undergoing a demographic and epidemiological transition resulting in a double burden of the disease; CVD is emerging as one of the major non-communicable diseases (NCD). ${ }^{4}$ A repeat cross-sectional study showed a threefold increase in the prevalence of hypertension over 25 years in the eastern part of Nepal. ${ }^{5}$ The prevalence of hypertension as reported by the national NCD risk factor survey in 2013 was $25.7 \%$ in adults aged $15-69$ years. $^{4}$

Although treatment of hypertension has been shown to prevent CVD, two-thirds of individuals diagnosed with hypertension are either untreated or inadequately controlled, and many of them are yet undiagnosed. ${ }^{67}$ About $30 \%-60 \%$ of patients with hypertension discontinue their medicine within the first year of treatment, and less than 20\%-65\% remain on treatment after 3 years. Of those who continue treatment, only about $40 \%-70 \%$ are adherent. $^{7-9}$ According to the latest national NCD survey in Nepal, 9 out of 10 patients with hypertension were not on medication. ${ }^{4}$ A population-based longitudinal study in a suburban community in Nepal showed that only one-third (34.3\%) of patients were highly adherent to medication, while a hospital-based cross-sectional study (2016) showed that $51.9 \%$ of patients were adherent to medication.

The recommendations for controlling hypertension at the population level include raising awareness, regimens that combine treatment with lifestyle modification and increasing adherence to medication. ${ }^{1011}$ However, implementation of these recommendations is often prone to failure due to various barriers, such as lack of awareness, poor adherence to medication, low motivation for lifestyle changes and lack of family support. A qualitative study on patient perspective of hypertension done in Canada found that patients struggled to define hypertension; only half of them (54\%) could recall their targeted blood pressure threshold. ${ }^{12}$ Other qualitative studies conducted in Malaysia ${ }^{13}$ and the USA $^{14}$ reported that their patients were not aware that hypertension could be asymptomatic, and the asymptomatic patients considered themselves healthy. Furthermore, patients believed that hypertension can be cured and that they can discontinue medicine when their blood pressure is normal. ${ }^{615-17}$ Patients also discontinued medicines due to fear of having to take medicines for life. ${ }^{14}$

It is also important to focus on the patients who are newly diagnosed with hypertension because these patients deny the condition at the beginning and perceive themselves to be at lower risk of complications. ${ }^{18}{ }^{19}$ When they accept the reality, these patients may experience psychological and emotional stress because of the realisation that hypertension is a lifelong disease. A qualitative study conducted to explore the experiences of patients with newly diagnosed hypertension in South Africa indicated that their patients had a fear of death due to the disease. ${ }^{19}$ They also had a feeling of rejections when the family members ignore their food needs. Moreover, patients had experienced more difficulties due to daily lifestyle changes, such as food habit and daily medicine intake. ${ }^{20}$ Therefore, it is important to assist newly 
diagnosed patients in coping with their disease and facilitating treatment adherence.

Most of the research conducted thus far in Nepal has been focused on medication adherence in patients diagnosed with prevalent disease(s). ${ }^{21} 22$ Moreover, previous studies have primarily focused on those patients who sought medical care, but not on those who did not seek medical care after diagnosis. Thus, this study aims to explore the barriers and facilitators to hypertension control among patients with newly diagnosed hypertension.

\section{METHODS}

\section{Study design and setting}

This is a qualitative study embedded in a larger cohort study, the Dhulikhel Heart Study (DHS), implemented through Dhulikhel Hospital, Kathmandu University in central Nepal. ${ }^{23}$ The first wave of the DHS was conducted between November 2013 and February 2015, which recruited 1073 adults 18 years of age or older and identified 321 (30\%) participants with hypertension in the community. ${ }^{24}{ }^{25}$ Blood pressure referral card was given to 161 participants with newly diagnosed hypertension in the community (blood pressure measurement of systolic blood pressure (SBP) $\geq 140 \mathrm{~mm} \mathrm{Hg}$ or diastolic blood pressure (DBP) $\geq 90 \mathrm{~mm} \mathrm{Hg})^{23}$ and were asked to go to a health institution for consultation. The present study was conducted from December 2015 to February 2016 among a subset of those participants with newly diagnosed hypertension of the DHS who provided consent to participate in focus groups on the topic of hypertension. The patients were enrolled after 9 months to 2 years from the first diagnosis of hypertension.

\section{Data collection}

\section{Focus group discussions}

We stratified participants with hypertension into four groups based on their treatment and care to maintain homogeneity within the groups: (1) those who did not seek healthcare at all; (2) those currently on treatment and are compliant; (3) those currently on treatment and are not compliant; and (4) those who were initially measured with high blood pressure in the survey, but their hypertension status was not confirmed in the hospital (ie, false positives). We measured medication compliance using the Morisky Medication Adherence Scale-8 (ㄷ2007 Donald E Morisky), ${ }^{26-28}$ which categorises adherence level into three groups-low adherence $(<6)$, medium adherence $(6$ to $<8$ ) and high adherence $(8)$. For the purpose of this study, we grouped patients with low and medium medication adherence into non-compliant group and patients with high medication adherence into compliant group.

We contacted 161 patients with newly diagnosed hypertension $(\mathrm{SBP} \geq 140 \mathrm{~mm} \mathrm{Hg}$ or $\mathrm{DBP} \geq 90 \mathrm{~mm} \mathrm{Hg}$ ) by phone and home visits to explore their status of treatment and care after the survey. We excluded 35 participants because of the following reasons: did not receive blood pressure referral card $(n=8)$, could not be contacted by phone and home visit $(n=23)$, death $(n=1)$, mental illness $(n=1)$ and were not newly diagnosed cases $(\mathrm{n}=2)$. The remaining 126 participants were divided into 'Group 1', 'Group 2', 'Group 3' and 'Group 4', as mentioned above.

Table 1 summarises the enrolment status of the 126 participants. From each group, we randomly selected participants and invited 80 for discussions, among whom 35 attended the discussion and 45 declined. The reasons for non-participation were busy work schedule $(n=23)$, out of town $(n=12)$, medical illness $(n=9)$ and death of a family member $(n=1)$.

\begin{tabular}{lccccc}
\hline Table 1 & Participants' enrolment status & \\
\hline Group & Total & $\begin{array}{l}\text { Invited for } \\
\text { FGD }\end{array}$ & Attended & Declined & $\begin{array}{l}\text { Not invited } \\
\text { for FGD }\end{array}$ \\
\hline Group 1 & 40 & 35 & 16 & 19 & 5 \\
Group 2 & 7 & 7 & 4 & 3 & 0 \\
Group 3 & 8 & 8 & 4 & 4 & 0 \\
Group 4 & 71 & 30 & 11 & 19 & 41 \\
Total & 126 & 80 & 35 & 45 & 46 \\
\hline
\end{tabular}

FGD, focus group discussion.

Focus group discussions (FGDs) were conducted using predetermined, open-ended guidelines. The guidelines were pretested among a group of eight patients with hypertension of the DHS study and necessary modifications were made. The discussion was based on three domains: (1) patients' knowledge, attitude and practices about hypertension, (2) barriers to healthcare, and (3) facilitators to healthcare. Questions were probed to get indepth information on the particular subject matter. The questions included 'What do you understand by hypertension?', 'To what extent, do you think hypertension is a serious disease?', 'What factors affect your hypertension treatment and follow up to care?' and 'What facilitates you to get the treatment?' We also collected participants' demographic information (age, occupation, gender). The principal investigator (SS) moderated all FGDs. We audiotaped the discussion and took notes during each session. Group size varied from 4 to 7 , and sessions lasted from 55 to 90 min. FGDs were conducted on Saturdays in a private space within Dhulikhel Hospital and in a school.

\section{Data analysis}

The audiotaped discussions were transcribed verbatim in Nepali by SS. Data were analysed using a thematic framework method. ${ }^{29}$ SS and AS read and reread three transcripts and independently coded them. The themes and codes were discussed and agreed on. SS then developed a codebook. SS further examined the transcripts line by line to identify the text units and categorised according to the codes using the Atlas.ti V.7 software. Analysis was finalised when all relevant texts were categorised. Data were then charted and interpreted. Selected quotes are reported in table 2 .

\section{RESULTS}

We conducted seven FGDs with 35 participants. The characteristics of the participants are presented in table 3 . The mean age of the participants was $45.9 \pm 11.6$ years. Most participants were male, from Newar ethnicity, with Hindu religion and were married. About $17.1 \%$ did not have formal education and $25.8 \%$ were unemployed.

Among those who declined to participate in this study $(n=45)$, the majority were male (68.9\%). The mean age of participants was $45.4 \pm 14.2$ years. Therefore, the characteristics of participants and non-participants, such as age and gender, were similar.

\section{Burden of hypertension}

The common terminologies for hypertension in the community were 'BP' (blood pressure), 'pressure' and 'pressure high'. A literal translation of blood pressure in Nepali is 'Uccha raktachap'; however, it was not popular in use. The participants said that hypertension was common, and its cases have been increasing in the community. 
Table 2 Example of coding, categorising and formulating themes

\begin{tabular}{|c|c|c|c|c|}
\hline Codes & Definition of codes & Subcategory & Category & Theme \\
\hline Fear of death & $\begin{array}{l}\text { Any reference to the patient's perceived fear of } \\
\text { death that motivates them to stick to the treatment } \\
\text { recommendations. }\end{array}$ & Fear of consequences. & Individual factor. & Facilitating factors. \\
\hline Self-awareness & $\begin{array}{l}\text { Any reference to the patient's self-awareness and } \\
\text { motivation to control the disease. }\end{array}$ & Self-awareness and self-control. & & \\
\hline Use of mobile & $\begin{array}{l}\text { Any reference to the use of a mobile device to set } \\
\text { reminders for taking medicines. }\end{array}$ & Self-reminding strategies. & & \\
\hline Daily routine & $\begin{array}{l}\text { Any reference to the creation of daily routine for } \\
\text { managing time to take medicine. }\end{array}$ & & & \\
\hline Carrying medicine & $\begin{array}{l}\text { Any reference to the patient carrying medicine when } \\
\text { they are out of home. }\end{array}$ & & & \\
\hline
\end{tabular}

It's like normal these days...people are dying...when a person dies, they say that he might have high blood pressure...if not, heart attack...nowadays, whoever dies, people say he might have died because of 'pressure'. (P2, male, group 1)

\section{Knowledge of hypertension}

A majority of participants defined hypertension in a variety of ways, linking it with its causes (poor diet, lack of physical activity, stress, alcohol and smoking), symptoms (dizziness, headache,

\begin{tabular}{|c|c|}
\hline Characteristics & $\begin{array}{l}\text { Participants }(\mathrm{n}=35) \\
\mathrm{n}(\%)\end{array}$ \\
\hline \multicolumn{2}{|l|}{ Age group } \\
\hline 20-39 & $7(20.0)$ \\
\hline $40-59$ & $23(65.7)$ \\
\hline$>60$ & $5(14.3)$ \\
\hline \multicolumn{2}{|l|}{ Gender } \\
\hline Male & $26(74.3)$ \\
\hline Female & $9(25.7)$ \\
\hline \multicolumn{2}{|l|}{ Ethnicity } \\
\hline Newar & $25(71.4)$ \\
\hline Brahmin & $5(14.3)$ \\
\hline Tamang & $4(11.4)$ \\
\hline \multicolumn{2}{|l|}{ Religion } \\
\hline Hindu & 31 (88.6) \\
\hline Non-Hindu & $4(11.4)$ \\
\hline \multicolumn{2}{|l|}{ Marital status } \\
\hline Married & $31(88.6)$ \\
\hline Not married & $4(11.4)$ \\
\hline \multicolumn{2}{|l|}{ Education } \\
\hline No formal education & $6(17.1)$ \\
\hline Primary-level education & $10(28.6)$ \\
\hline Secondary-level education & $13(37.1)$ \\
\hline High school or more & $6(17.1)$ \\
\hline \multicolumn{2}{|l|}{ Occupation } \\
\hline Employed & $6(17.1)$ \\
\hline Self-employed* & $20(57.1)$ \\
\hline Home maker & $6(17.1)$ \\
\hline Otherst & $3(8.7)$ \\
\hline
\end{tabular}

*Self-employed includes business and agriculture.

tOthers include non-paid job, student and unemployed. anger and eye burn) and complications (heart attack, paralysis and eye problem). However, three participants could not define it. All participants, except four, did not know the normal blood pressure range.

Stress was repeatedly mentioned as a cause of hypertension. Many of them linked it with diet (fatty, spicy and salty food) and lack of physical activity. Only five participants reported age and heredity as a cause of hypertension. Three participants believed that there is no definite cause of hypertension and anyone can have it irrespective of one's lifestyle.

We also encountered misconceptions. For examples, hypertension might occur when blood is spoiled 'ragat bigrera' and when the body is weak; it could be transmitted through breathing; and it can always be cured 'Niko huncha' through strict diet control.

I sleep together with my sons, and it (hypertension) transmits through breathing. I doubt that it will affect my heart. (P1, male, group 1)

Well, that's [hypertension] a curable disease. [...]. Every disease can be cured if we eat on time. (P5, male, group 4)

\section{Barriers to hypertension treatment Individual factors}

The major individual-level barriers reported in FGDs were challenges in modifying behaviour, absence of symptoms, perceived seriousness of hypertension and reluctance to take medicine.

\section{Challenges in behaviour modification}

Participants were aware of the benefit of lifestyle modification (diet and exercise), but it was difficult for them to practise in daily life. The most commonly reported barriers for diet control were food craving and food taste. Male participants emphasised their habits of drinking alcohol and smoking:

At home, I was told not to drink as I have 'pressure', but what to do? I get severe headache if I do not drink. It heals after I have it. (P7, male, group 1)

For exercise, participants frequently reported laziness and bad weather as reasons for not exercising. Several reported a busy schedule and comorbidities such as musculoskeletal pain that limit their physical activities. An interesting perception emerged during discussions regarding the benefits of a morning walk. All participants thought that walks only in the morning are beneficial in blood pressure control. Therefore, participants who were busy in the morning did not have other exercise plans. 
I exercised for a week, but I got head cold. I had severe headache, might be due to cold? I went early in the morning at around $5 \mathrm{am}$ because I had to be in the kitchen at $7 \mathrm{am}$. [I] have to go early in the morning, so I quit as it was difficult. Otherwise, I used to go for morning walk. Now I drink lemon water every day, four to five glasses in the morning. (P1, female, group 4)

We also found misconceptions that the morning walk is not necessary for lean people, and it might also raise blood pressure due to increase in body temperature.

Morning walk can cause rise in blood pressure...body gets warmer. (P1, female, group 1)

\section{Absence of symptoms}

All groups believed that an absence of symptoms, such as headache, anger and dizziness, indicates that their blood pressure is normal. Non-adherent participants reported that they visit a doctor only when they feel their blood pressure is high. The participants in a group who did not seek healthcare after diagnosis even refused to believe that they had hypertension.

[My] pressure is not high. It's not high...for two to four days, it was $130 / 100,140 / 100$ then decreased. I had a headache today, I knew my pressure had increased, then I took medicine like cetamol [Paracetamol]. It gets cured by tomorrow or the day after tomorrow. So, [I] don't have any reason to go [to health care]. (P1, male, group 1)

Sometimes I go [hospital], sometimes I do not go. One knows when the pressure gets high. I go for check-up when I know it. (P2, male, group 3)

\section{Perceived seriousness of hypertension}

Hypertension is not considered serious unless there is a symptom or a complication. Several participants who did not seek healthcare had not informed their families about their hypertension status. Three participants said that hospital is only for big problems, so they either visit local pharmacies or their neighbours who have blood pressure monitoring machine to check their blood pressure when they have headache or dizziness.

We cannot ignore own health, but for a small problem [BP], I feel like, why to go [hospital]? So, I go to a medical shop [local pharmacy]. (P4, female, group 3)

\section{Reluctance to take medicine}

Participants who did not seek healthcare after diagnosis were reluctant to initiate medicine because of its long-term intake and the associated cost. Therefore, instead of visiting a hospital, they first wanted to change diet and exercise:

We should not take medicine for pressure [blood pressure] and sugar [diabetes]. We should control them ourselves [by lifestyle modification]. (P2, female, group 1)

All groups believed that ayurvedic and herbal medicines, such as aloe vera, fenugreek, bitter gourd and neem leaves, help to reduce blood pressure. Participants on medication used ayurvedic medicines as supplement to allopathic medicine. During discussion, a non-adherent participant asked if she could quit antihypertensive medicine:

...It's fine to take [Ayurvedic medicine] when one has not started antihypertensive medication and the blood pressure is a little high. Now that I have already started taking [anti-hypertensive] medicine, can I quit it or not? (P4, female, group 3)
Non-adherent participants reported that they forgot to take medicines because of their busy schedule, and they were not habitual in taking medicine daily.

\section{Sociocultural factors}

Participants discussed many socioculture-related barriers, including a culture of eating together in the family, feasts and festivals, and social drinking. Participants reported that it is burdensome and time-consuming to have separate meals prepared for them. Some said their families ignore their food needs. The feasts and festivals serve foods that are fatty and salty, but many felt obligated to attend for social reasons. Male participants reported difficulty in avoiding or reducing alcohol intake because it is expected when they get together with friends.

It's like this, in our villages, we are quite busy with our works. It's difficult if we cannot eat the same food...it's difficult because of time. So, it's difficult for us. (P1, female, group 1)

If [I] do not go [to attend feasts], [they] will get angry. [I] don't eat much, just little, and little. (P4, female, group 3)

The only thing we eat when we are with our friends is alcohol. When we gathered daily, we drink daily. And, sometimes we don't gather, we do not drink for a month (giggle). It happens like that. (P2, male, group 1)

\section{Healthcare-related factors}

Among participants who visited health institutions, the communication gap was overwhelmingly reported as a barrier to follow-up and adherence to treatment. A majority of participants complained that doctors do not explain enough about high blood pressure because they have limited consulting time.

Telling the truth, doctor told me...I checked my pressure. After check-up, I was told to take medicine. [He said], 'You have pressure, so we give you simple medicine with low dose'. Then I forgot to ask, and he also forgot to tell me. [...] I was not told anything. So, I am telling the truth, I asked people who has heart disease to get the information regarding what food to eat, which food increases it, and which food controls pressure. (P2, male, group 2)

Participants were not aware how much exercise is adequate and how much salt is too much. One participant mentioned that adding water would reduce the amount of salt.

The lentils were salty, $[\mathrm{I}]$ added water and ate. (P1, male, group 3 )

The participants preferred to see senior doctors, when possible. Several participants reported long waiting hours as an inhibitory factor, and few reported their providers being unwelcoming.

Sometimes these things happen...[health workers] say something that we don't know. So, when we don't know, we get confused. We don't know where to go and who to ask. We feel like it was worthless to go there [...]. (P4, female, group 3)

Yes, it takes a whole day. If we have to check that blood, urine and others, then they will give report only after $2 \mathrm{pm}$. And, they go for lunch at $1 \mathrm{pm}$. Then after taking report, we need to find a doctor to show them. That's why, it takes a whole day, just to measure a pressure. It takes whole day even if we come. So, its laziness. (P2, female, group 3)

Two female participants who did not seek healthcare after diagnosis mentioned unaffordable cost as a reason for not visiting hospital. The financial burden was not reported by patients who were currently on medication, except two women who were financially dependent on their family members.

Even if I feel like going, money does not come for free, so what to do? If I go to hospital it requires money. (P1, female, group 1) 
Well, the expense...its husband's...I don't have earnings... sometimes I feel awkward. Why should I feel awkward with my own husband? Well, it's embarrassing to keep asking. (P2, female, group 3)

\section{Facilitators to treatment and follow up}

Patients discussed facilitating factors such as fear of consequences, patient's self-awareness and self-control, self-reminding strategies, social support, and counselling by healthcare providers.

The participants who continued to seek healthcare and who were adherent to medication reported that their main motivation was the fear of health consequences from uncontrolled blood pressure. The participants who had seen health consequences in their own family or community were more motivated to adhere to treatment.

In my case, first of all, my mother had it. She had paralysis. Then my father had it. And, then my elder brother had it, elder sister had it. This 'raktachap' [hypertension] is in my family history. That's why, I should say I am a bit more careful. I go for timely checkup. (P4, male, group 2)

In all FGDs, participants emphasised that the patients themselves should be careful about their disease. Participants on medication reported the strategies that helped them to remember taking medicines, such as carrying medicines every day, creating daily routine to manage time for medicine, setting reminders in mobile and keeping medicine by bedside.

But it is for our body. Others won't do for our body. Should be done by ourselves. If not controlled at once, we can control it slowly and slowly. (P2, male, group 2)

In all FGDs, participants stated the importance of family support to modify the lifestyle, to take medicines and to seek healthcare.

I don't feel like eating with less salt, but my daughter cooks food with less salt thinking that her father has disease and if he eats more salt, it will increase it [BP]. ...I take medicine at $8 \mathrm{pm}$. I do not remember while watching TV. I keep on doing other things. My daughter then ask me, 'it's already 8 , have you taken your medicine?' then, I take it. (P2, male, group 2)

Family gives pressure, like my wife says why should I drink [alcohol]. Then I also feel what difference would it make if I do not drink [alcohol] for one ortwo days and then I leave it. (P7, male, group 1)

Similarly, participants also highlighted the importance of health counselling regarding the disease. An adherent participant repeatedly praised a doctor for giving him enough time during consultation:

I told you, we cannot see him [the doctor] before two hours though we reached earlier. He has such a good habit, please do not mind that I am telling about him a lot, what he does is that he gives half an hour to every patients. He goes thoroughly through the paper to check when he started, then asks us, and then confirms. If he doubts, then he measures pressure. He confirms it and then prescribes medicine. (P2, male, group 2)

The study found similar perceptions regarding hypertension and its treatment among participants from different FGDs. All groups believed that hypertension is not asymptomatic; the absence of symptoms indicates that their blood pressure is normal. The knowledge and belief on medication among those participants who were on medications were not different from those who did not seek healthcare. However, participants who continued to seek healthcare and who were adherent to medications were more aware of the health consequences than those who did not
Table 4 Reported barriers and facilitating factors to hypertension treatment

\begin{tabular}{|c|c|c|}
\hline Categories & Barriers & Facilitators \\
\hline Individual factor & $\begin{array}{l}\text { Challenges in behaviour } \\
\text { change (diet and exercise). } \\
\text { View that exercise is dangerous } \\
\text { for patients with hypertension. } \\
\text { Does not feel symptoms. } \\
\text { Lack of perceived seriousness } \\
\text { of the disease. } \\
\text { Fear of dependence on } \\
\text { medication and beliefs on } \\
\text { traditional medicine. }\end{array}$ & $\begin{array}{l}\text { Fear of complications and death } \\
\text { due to the disease. } \\
\text { Self-motivated attitude to } \\
\text { control and manage own } \\
\text { disease. } \\
\text { Use of reminders such as } \\
\text { mobile, creation of daily } \\
\text { routine for medicine intake and } \\
\text { carrying medicine. } \\
\text { Take one's medication at the } \\
\text { same time each day; use a } \\
\text { medication container. }\end{array}$ \\
\hline $\begin{array}{l}\text { Sociocultural } \\
\text { factors }\end{array}$ & $\begin{array}{l}\text { Lack of family support in } \\
\text { addressing food needs. } \\
\text { Cooking separate food for the } \\
\text { patient is time-consuming and } \\
\text { burdensome. } \\
\text { Uncontrolled diet in feasts and } \\
\text { festivals. } \\
\text { Social drinking. }\end{array}$ & $\begin{array}{l}\text { Family support in diet control, } \\
\text { medicine intake, and treatment } \\
\text { and follow-up to care. }\end{array}$ \\
\hline $\begin{array}{l}\text { Healthcare-related } \\
\text { factors }\end{array}$ & $\begin{array}{l}\text { Lack of counselling from } \\
\text { providers. } \\
\text { Preference to see senior } \\
\text { doctors. } \\
\text { Providers' negative behaviours. } \\
\text { Unaffordability of treatment. }\end{array}$ & Counselling by providers. \\
\hline
\end{tabular}

seek healthcare. These participants also take hypertension seriously than those who did not seek healthcare. Those who did not seek healthcare had not even informed their families about their hypertension status (table 4).

\section{DISCUSSION}

In this study, we explored patients' knowledge and attitude regarding hypertension and also explored their perceived barriers and facilitators to hypertension treatment and care. The study showed that participants had inadequate knowledge and misbeliefs regarding hypertension. Hypertension was rising in the community and was perceived as a curable disease. The major barriers to treatment and follow-up included absence of symptoms, reluctance to take medicine, low perceived seriousness of hypertension, difficulty in modifying behaviour, lack of family support and lack of provider counselling. Fear in hypertension consequences and family support were the major facilitating factors for treatment and follow-up.

The participants had varied understanding of hypertension, and they mainly linked it with its causes, symptoms and complications. The findings are similar to those reported in Canadian and US studies highlighting patients' difficulties in defining hypertension. ${ }^{12} 30$ Stress was frequently reported as a major cause of hypertension in this study. Studies reported that when patients view stress as an underlying cause of hypertension, they are more likely to take the disease as acute and episodic, and thus are non-compliant to treatment compared with others. ${ }^{13} 1417$

Hypertension was perceived as a common disease in the community, which is congruent with other studies in Nepal and India. ${ }^{3132}$ Many participants who did not seek healthcare in our study did not perceive hypertension as a serious disease, similar to the CVD perception study in Nepal. ${ }^{33}$ Similar to the studies in Nigeria, USA and Malaysia, ${ }^{13} 1416$ asymptomatic patients in our study also considered themselves healthy. They changed their diet and sought healthcare based on their symptoms. Studies 
have shown that the asymptomatic nature of hypertension also complicates the communication between patients and health providers as patients do not trust their providers; the providers prioritise the risk factor-based treatment and the patients prioritise the symptoms-based treatment. ${ }^{13}{ }^{14}$ Given the patients who did not seek care after being diagnosed as hypertensive in our study, it is of utmost importance to closely follow and encourage these patients to visit the hospital for further evaluation.

The adherence to medication is impacted by patients' misbeliefs and their behaviour. Participants in this study had several misbeliefs regarding hypertension: that hypertension can be cured, that it is non-inheritable, that medicine can be discontinued when blood pressure has normalised and that traditional medicines work better than allopathic. These beliefs contributed to poor medication adherence and discontinuation of medical care, which have also been reported in studies from Columbia, South Africa and Nepal. ${ }^{6} 1921$ Furthermore, patients preferred lifestyle modifications to medications due to fear of having to take medicines for life, which is another important barrier to initiating and adhering to medications in this study, like in other studies. ${ }^{1314}$ This study also identified that patients forget to take medication when they travel, have busy work and feel lazy. A study conducted among patients with hypertension in an Uzbekistan hospital reported that the most essential reasons for non-adherence were patients' psychology and knowledge about taking drugs when having felt a rise in blood pressure (44.7\%), switching to traditional therapy (14.4\%), being afraid of addiction $(12.9 \%)$, effects of medications $(7.6 \%)$ and forgetting to take the drugs $(7.6 \%){ }^{34}$

Adequate physical activity and healthy diet can prevent and help control hypertension. ${ }^{11}$ Although the participants in this study were aware of healthy lifestyle changes, they did not apply those in daily life. This finding has been reported elsewhere. ${ }^{61933}$ Furthermore, participants had several misconceptions regarding exercise and diet. They believed that only morning walks are effective physical activity in controlling blood pressure; patients with high blood pressure should not exercise; and adding water reduces sodium in salty food. These misbeliefs indicate participants' low awareness level as well as lack of counselling from healthcare providers.

Lack of counselling is a major barrier to treatment adherence. ${ }^{61427}$ It was surprising to find that our participants who were on medication did not know how often to visit the hospital for care. Their knowledge and belief on medication were not different from those who did not seek healthcare. This indicates that there is plenty of room for improvement in counselling. It is important to train healthcare professionals on providing patient-centred counselling education. It is also equally important to build trust with patients for effective communication. ${ }^{65}$ The SBP intervention trial study showed that participatory and interpersonal communication is the best type of intervention to change patients' behaviour and facilitate higher treatment adherence. ${ }^{27}$

Our study revealed that the facilitators of behaviour modification and medication adherence were fear of consequences, reminder strategies, self-awareness and self-control, family support, and counselling by healthcare providers. A study in Nigeria showed that $86 \%$ of patients comply with doctors' appointments out of fear of complications and the desire to control their blood pressure. ${ }^{17}$ Given the low health awareness and low access to healthcare in resource-constraint settings, it is also important to provide care in the community and enable people to self-monitor their blood pressure levels at home. It is important that patients know their blood pressure number as well as the normal blood pressure range. Several studies have emphasised the importance of community-based programmes in preventing chronic diseases and supporting patients with their self-management. Studies have also emphasised the role of family member support to control hypertension. ${ }^{6}{ }^{6}$ In our study, in addition to family, participants reported consulting patients with prevalent chronic disease in their communities regarding their diet. This demonstrates the need for family and community education on hypertension.

This is the first qualitative study of its kind in Nepal, which aimed to explore barriers and facilitators to treatment among patients with newly diagnosed hypertension in a suburban community in Nepal. The study has several limitations. The exploratory nature of this qualitative study, confinement to Nepal with DHS participants only and the small sample size limit the generalisability of our findings to other populations. Moreover, the study participants are from a suburban area, so it is probable that the findings may not be representative of other newly diagnosed patients in urban or rural areas in Nepal. However, a qualitative study is designed to understand the phenomenon and not to measure variables. ${ }^{19}$ There were more male participants in our study. Many women did not show up because they were occupied with domestic chores in their families. Although men may hold different views, we did not find remarkable differences between male and female opinion. Since patients were newly diagnosed, it had not been long since they started their medications. So it is possible that there might be other medication-related barriers that we could explore from previously diagnosed cases.

Despite these limitations, our study has provided indepth view of personal, social and healthcare-related facilitators and barriers to hypertension management in Nepal.

\section{Key messages}

What is already known about this subject?

- Recommendations for controlling hypertension at the population level include raising awareness, regimens that combine treatment with lifestyle modification and increasing adherence to medication.

- However, implementation of these recommendations is often prone to failure due to various barriers related to patients' individual behaviour, social and healthcare-related factors.

\section{What does this study add?}

- Research on exploring barriers and facilitating factors to hypertension among patients with newly diagnosed hypertension was lacking in Nepal.

- The reported major barriers explored by the study were perceived feeling of wellness, difficulty in changing habits, reluctance to take medicines, lack of family support and lack of provider counselling.

- Fear of consequences of the disease and family support were major facilitating factors to treatment adherence.

How might this impact on clinical practice?

- The findings of the study can be used to design appropriate health interventions to improve hypertension management in low-income countries. 


\section{CONCLUSION}

In this suburban community, patients with newly diagnosed hypertension had inadequate knowledge and misbeliefs regarding hypertension and its treatment. Therefore, health interventions designed to improve hypertension outcome should focus on developing and disseminating appropriate health information, with a special focus on the asymptomatic and acute nature of hypertension, importance of regular medication intake and lifestyle changes, and consequences of hypertension. The involvement of healthcare providers, family members and community in education programmes would be helpful for patients to cope with their diseases and to change their existing beliefs.

Acknowledgements We would like to acknowledge the contribution of all study participants and the human resource and logistical support from the Department of Community Programs, Dhulikhel Hospital. Thanks to Ms Naveena Shrestha and Ms Binita KC from Dhulikhel Hospital for their help in data collection. Use of the MMAS is protected by US copyright laws. Permission for use is required. A licence agreement is available from Donald E Morisky, 294 Lindura Court, Las Vegas, NV 89138-4632, USA; dmorisky@gmail.com.

Contributors SS conceptualised the study, collected, transcribed and analysed the data, and drafted and reviewed the manuscript. AS contributed to designing the research study, analysing the data and reviewing the manuscript. BMK contributed to research design. ALF contributed significantly to manuscript writing. All authors contributed to refinement and approved the final manuscript.

Funding SS and NS were supported by the Laughlin family.

Competing interests None declared.

Patient consent Obtained.

Ethics approval The study was approved by the Kathmandu University School of Medical Sciences Institutional Review Committee and the University of Washington Division of Human Subjects.

Provenance and peer review Not commissioned; externally peer reviewed.

Data sharing statement The data are not available to share.

\section{REFERENCES}

1. WHO. Global status report on non-communicable disease. Switzerland, 2014.

2. WHO. A global brief on hypertension: Silent killer, global public health crisis. World Health Day. Switzerland: World Health Organization, 2013.

3. WHO. Noncommunicable diseases in the South-east asia region: Situation and response. India: World Health Organization, 2011.

4. Aryal KK, Neupane S. Non communicable diseases risk factors: STEPS Survey Nepal 2013. Kathmandu, 2014

5. Vaidya A, Pathak RP, Pandey MR. Prevalence of hypertension in nepalese community triples in 25 years: A repeat cross-sectional study in rural Kathmandu. Indian Heart J 2012:64:128-31.

6. Legido-Quigley H, Camacho Lopez PA, Balabanova D, et al. Patients' knowledge, attitudes, behaviour and health care experiences on the prevention, detection, management and control of hypertension in Colombia: a qualitative study. PLoS One 2015; 10:e0122112.

7. Bosworth $\mathrm{HB}$, Olsen MK, Oddone EZ. Improving blood pressure control by tailored feedback to patients and clinicians. Am Heart J 2005; 149:795-803.

8. Degli Esposti E, Sturani A, Di Martino M, et al. Long-term persistence with antihypertensive drugs in new patients. J Hum Hypertens 2002;16:439-44.

9. Degli Esposti L, Di Martino M, Saragoni S, et al. Pharmacoeconomics of antihypertensive drug treatment: an analysis of how long patients remain on various antihypertensive therapies. J Clin Hypertens 2004;6:76-82.

10. Khatib R, Schwalm JD, Yusuf $S$, et al. Patient and healthcare provider barriers to hypertension awareness, treatment and follow up: a systematic review and metaanalysis of qualitative and quantitative studies. PLoS One 2014;9:e84238.
11. Chobanian AV, Bakris GL, Black HR, et al. The seventh report of the joint national committee on prevention, detection, evaluation, and treatment of high blood pressure: the JNC 7 report. JAMA 2003;289:2560-71

12. Jolles EP, Padwal RS, Clark AM. A qualitative study of patient perspectives about hypertension. ISRN Hypertension March 5, 2013

13. Shima R, Farizah MH, Majid HA. A qualitative study on hypertensive care behavior in primary health care settings in Malaysia. Patient Prefer Adherence 2014;8:1597-609.

14. Kronish IM, Leventhal $H$, Horowitz CR. Understanding minority patients' beliefs about hypertension to reduce gaps in communication between patients and clinicians. J Clin Hypertens 2012;14:38-44.

15. Okwuonu CG, Ojimadu NE, Okaka El, et al. Patient-related barriers to hypertension control in a Nigerian population. Int J Gen Med 2014;7:345-53.

16. Odusola AO, Hendriks $M$, Schultsz $C$, et al. Perceptions of inhibitors and facilitators for adhering to hypertension treatment among insured patients in rural Nigeria: a qualitative study. BMC Health Serv Res 2014;14:624.

17. Osamor PE, Owumi BE. Factors associated with treatment compliance in hypertension in southwest Nigeria. J Health Popul Nutr 2011;29:619-28.

18. Weaver NF, Murtagh MJ, Thomson RG. How do newly diagnosed hypertensives understand 'risk'? Narratives used in coping with risk. Fam Pract 2006;23:637-43.

19. Mothiba T, Malema R, Lekhuleni M. The experiences of the newly diagnosed hypertensive patients admitted into tertiary hospital campus in Limpopo Province, South Africa.. African Journal for Physical, Health Education, Recreation and Dance (AJPHERD) 20 13:213-21.

20. Adams OP, Carter AO, Knowledge CAO. Knowledge, attitudes, practices, and barriers reported by patients receiving diabetes and hypertension primary health care in Barbados: a focus group study. BMC Fam Pract 2011;12:135.

21. Bhandari $B, B$ Battarai $M$, Bhandari $M$. adherence to antihypertensive medications: population based follow up in eastern nepal. J Nepal Health Res Counc 2015:13:38-42.

22. Khan GM, Thapa RK, Khakurel A. Medication adherence and blood pressure control among hypertensive patients of pokhara valley. JHAS 2013;3:64-7.

23. Karmacharya BM. Epidemiology of cardiovascular diseases risk factors and hypertension in a community-based suburban population in nepal: University of Washington, 2015

24. Shrestha A, Koju RP, Beresford SA, et al. Food patterns measured by principal component analysis and obesity in the Nepalese adult. Heart Asia 2016;8:46-53.

25. Karmacharya BM, Koju RP, LoGerfo JP, et al. Awareness, treatment and control of hypertension in Nepal: findings from the Dhulikhel Heart Study. Heart Asia 2017:9:1-8

26. Morisky DE, Ang A, Krousel-Wood $M$, et al. Predictive validity of a medication adherence measure in an outpatient setting. J Clin Hypertens 2008;10:348-54.

27. Berlowitz DR, Foy CG, Kazis LE. Effect of intensive blood-pressure treatment on patient-reported Outcomes. N Engl J Med 2017;377:733-44.

28. Morisky DE, DiMatteo MR. Improving the measurement of self-reported medication nonadherence: response to authors. J Clin Epidemio/ 2011;64:255-7.

29. Ritchie J, Spencer L. Qualitative data analysis for applied policy research. The qualitative researcher's companion, 2002:305-29.

30. Rose LE, Kim MT, Dennison CR, et al. The contexts of adherence for African Americans with high blood pressure. J Adv Nurs 2000;32:587-94.

31. Oli N, Vaidya A, Thapa G. Behavioural Risk Factors of Noncommunicable Diseases among Nepalese Urban Poor: A Descriptive Study from a Slum Area of Kathmandu. Epidemiol Res Int 2013:2013:1-13.

32. Kusuma YS. Perceptions on hypertension among migrants in Delhi, India: a qualitative study. BMC Public Health 2009;9:267.

33. Vaidya A, Aryal UR, Krettek A. Cardiovascular health knowledge, attitude and practice/ behaviour in an urbanising community of Nepal: a population-based cross-sectional study from Jhaukhel-Duwakot Health Demographic Surveillance Site. BMJ Open 2013;3:e002976

34. Malik A, Yoshida Y, Erkin T, et al. Hypertension-related knowledge, practice and drug adherence among inpatients of a hospital in samarkand, uzbekistan. Nagoya J Med Sci 2014;76(3-4):255-63.

35. Murphy K, Chuma T, Mathews C, et al. A qualitative study of the experiences of care and motivation for effective self-management among diabetic and hypertensive patients attending public sector primary health care services in South Africa. BMC Health Serv Res 2015;15:303. 